\title{
Auditory monitoring in ototoxicity
}

\section{Lilian Cassia Bornia Jacob ', Fabrina Pavia Aguiar ${ }^{2}$, Aline Aparecida Tomiasi ${ }^{3}$, Samira Natacha Tschoeke ${ }^{4}$, Raquel Fava de Bitencourt ${ }^{5}$}

Keywords: medication, monitoring, neoplasms, hearing loss.

\section{Summary}

\begin{abstract}
Some pharmaceutical products are capable of damaging the human auditory system. Technological progress has provided numerous resources to monitor hearing but there still is some controversy regarding the selection of the most sensitive and specific tests. Objective: to analyze audiological procedures used in the auditory monitoring of individuals exposed to ototoxic medication. Methods: we searched the MEDLINE and LILACS literature databases, using terms pertinent to audiological monitoring, ototoxicity and cancer. The pertaining literature analysis identified two procedures often used worldwide for the early detection of auditory lesions induced by ototoxic pharmaceutical drugs: highfrequency audiometry and evoked otoacoustic emissions. Both allow early identification of hearing disorders before changes are seen in conventional pure-tone audiometry and, consequently, before speech understanding is compromised. Conclusion: we suggest a hearing monitoring protocol, considering the patient's capability to respond to behavioral tests and monitoring timing (first test/follow up). For cancer patients, hearing monitoring should be performed in the patient's treatment venue.
\end{abstract}

${ }^{1}$ PhD. Professor at the Speech and Hearing Therapy School and also of the Master's Program in Communication disorders of the Tuiuti University of Paraná. ${ }^{2}$ M.S. in Communications Disorders - Tuiuti University of Paraná. Speech and Hearing Therapist.

${ }^{3}$ M.S. Student in Communications Disorders - Tuiuti University of Paraná. Speech and Hearing Therapist.

${ }^{4}$ M.S. Student in Communications Disorders - Tuiuti University of Paraná. Speech and Hearing Therapist.

${ }^{5}$ M.S. in Communications Disorders - Tuiuti University of Paraná. Speech and Hearing Therapist. Universidade Tuiuti do Paraná.

Mailing Address: Lilian Jacob - Rua Prof. Pedro Viriato Parigot de Souza 1100 bloco 04 apto 703 Curitiba PR 81200-100. CAPES Scholarship.

Paper submitted to the ABORL-CCF SGP (Management Publications System) on October 11th, 2005 and accepted for publication on July 26 th, 2006. cod. 1503. 


\section{INTRODUCTION}

Hearing loss in adults may cause a number of psychosocial changes, because hearing sensitivity deficits and the problems related to speech understanding affect an individuals' life style. In children, at the age of speech development, the consequences of sensorial deficits, such as this one, may be even more disastrous. Since oral language development depends much on hearing, a hearing impairment is considered severely disabling, for it may cause speech development delays, schooling difficulties, social and emotional disorders.

Hearing alterations may be caused by different etiologic factors, being them congenital or acquired, and it also presents different degrees and types. Among the causes of acquired hearing impairment we have the use of some ototoxic substance that causes transitory or definitive alteration in auditory and vestibular functions ${ }^{1}$.

Research interest and investment in this field have come to provide knowledge on the different types of drugs that may cause medication-related ototoxicity.

Besides medication-related ototoxicity, damage to the hearing apparatus may occur from exposure to other physical agents such as noise, chemicals and heavy metals such as insecticides, toluene, styrene, ethylbenzene, carbon monoxide, carbon disulfide, lead and mercury, among others ${ }^{2-4}$. Notwithstanding, the present study will focus on the exposure to medication which are toxic for the human ear and the procedures currently available for the early diagnosis of hearing alterations caused by such exposure.

In recent years, the influence of chemotherapeutic agents over the hearing function, especially cisplatin and carboplatin has been studied by some researchers based on their action on the hearing system, causing tinnitus and hearing sensitivity alterations in some individuals under treatment with such drugs.

Thus, the ototoxic potential of such agents is being documented $^{5-9}$, especially among pediatric patients, in whom the incidence of bone tumors is greater. In the adult population the incidence of head and neck cancer is on the rise, and those patients under chemotherapeutic treatment may develop hearing impairment ${ }^{10}$.

When discussing the pediatric population, not only cancer treatment is important, but it is also of the uttermost importance to consider the social aspects related to the disease, since the child is inserted in a family and school context. Cure should be based not only on the biological recovery, but also in the well being and the patient's quality of life. In these regards, from the very beginning of treatment, the patient should not be deprived of hearing monitoring.

This discussion on the need to establish a hearing assessment protocol for the population of patients ex- posed to ototoxic agents is nothing new. Back in 1984, Fausti et al. ${ }^{11}$ already pointed this need out, and based on the selection of some studies on the early detection of ototoxicity caused by antineoplastic agents, they concluded that their effect on hearing was well documented, however there was still no consensus among researchers on which of the methods would be the one most suitable for hearing monitoring.

Hearing monitoring should allow for the lesion to be identified before there is damage to the tonal thresholds on conventional frequencies and, consequently, impair the individual's speech recognition. Thus, we understand that to monitor an individual under treatment by an ototoxic agent means to try, whenever possible, to preserve his/her hearing, or to detect early on a hearing loss and minimize its consequences to the individual's life by means of proper medical and hearing treatments.

Monitoring should be carried out since it provides early evidences of dose limits for hearing loss, thus allowing for preventing or mitigating ototoxicity severity, and when hearing loss is certain, there is the possibility of early hearing rehabilitation through the fitting of an individual hearing amplification device.

In this process, besides needing an otolaryngologist and a speech and hearing therapist in the multidisciplinary team, often times the psychologist is crucial, especially when the individual at stake is a teenager, struggling to accept the need for a hearing aid, or even to provide emotional support for the family that is frail at times of severe illnesses such as cancer, and also needs to come to terms with hearing loss.

Despite all procedures and equipment available for the hearing monitoring of individuals exposed to potentially ototoxic drugs, in most centers this population is seen without an effective program implemented to assess hearing, and interfere early on in cases when there already is hearing loss installed.

Analyzing the existing literature in these regards we see two procedures that have been used at a worldwide level for the early detection of ototoxic drug-induced hearing loss: high frequency audiometry and evoked otoacoustic emissions, notwithstanding, despite the availability of international assessment protocols, we still need to discuss the clinical application of such procedures as far as hearing monitoring is concerned.

Having said that, the goal of our present study was to survey the literature, check and analyze the audiological procedures used in the hearing monitoring of those individuals exposed to ototoxic medication. We surveyed the MEDLINE and LILACS medical databases, based on using the keywords for the following themes: hearing monitoring, ototoxicity and cancer. We also surveyed other electronic sites related to audiology such as the American Speech-Language-Hearing Association (ASHA), 
American Academy of Otolaryngology - Head and Neck Surgery (AAO-HNS), American Academy of Audiology, International Society of Audiology, Brazilian Society of Pediatrics, Brazilian Association of Otorhinolaryngology/Neck and Facial Surgery, Brazilian Society of Speech and Hearing Therapy, and the Brazilian Association of Otorhino-pediatrics.

As a result of this electronic search we found about 1,400 papers. The criteria used to select the studies were: publication between January of 1980 and July of 2005; clinical assays with adults or children, stressing the protocols used for auditory monitoring.

\section{LITERATURE REVIEW}

Aguiar $^{12}$ carried out a study with a number of drugs that may affect the auditory and vestibular systems either centrally or peripherally, and developed a summary of all the results published by some researchers, shown on Table 1.

In 1997 Moussalle et al. ${ }^{13}$ highlighted the fact that drug-induced ototoxicity should attract multidisciplinary medical interest, since the use of such drugs may involve liver and kidneys, and they are prescribed by all medical specialties, often times inadequately and as a first choice treatment, having its ototoxic potential totally disregarded and sometimes not believed.

Having in mind the hearing alterations caused to those patients who use ototoxic agents, it becomes paramount to monitor their hearing, thus allowing for an early diagnosis and identification of the lesion progression. Within these lines, after detecting the alterations caused to the patient's hearing health, actions such as the use of alternative treatment modalities, dose reduction or drug change, or even keeping the status quo but preparing the family for an eventual hearing loss, may be taken by the specialist ${ }^{14,15}$.

It is agreed upon among researchers in this field that hearing alterations caused by the use of ototoxic drugs starts on the basal cochlea, affecting high frequencies, and it may evolve towards the cochlear apex and later affect low and middle range frequencies, thus impacting all speech frequencies ${ }^{16-22}$, however, there are some controversies regarding the action mechanisms of these agents and their effect on hearing ${ }^{16,19,21,22}$.

Because of variables such as type of agent; dose duration; serum level and drug build up effect; renal disorders; individual susceptibility; hearing monitoring onset after treatment onset; among others; there are some aspects that require investigation. Among the latter we may think of the very hearing loss reversibility; affected areas of the hearing apparatus; the alteration rate of progression and the procedure able to detect any auditory lesion as early as possible.

According to reports from researchers that approach such themes, the hearing tests to be carried out during monitoring include conventional and high frequency audiometry, speech recognition tests, acoustic immittance measures and, for children, evoked otoacoustic emissions, Brain Stem Evoked Response Audiometry (BERA), and Electrocochleography (ECOGh) ${ }^{6,18,19,23,24}$.

In 1994 a committee made up of members of the American Speech-Language-Hearing Association (ASHA) ${ }^{25}$ presented some guidelines for hearing monitoring of individuals who are undergoing the use of cochleotoxic medication. According to this committee, it is important that the first audiological evaluation be carried out before drug therapy onset. When this is not possible and depending on the drug used, this assessment should happen no later than 24 hours of the first dose administration (in the case of chemotherapeutic agents such as cisplatin), and within the first 72 hours when the treatment is carried out with antibiotics such as aminoglicosides. The monitoring program should be set up according to the type of ototoxic medication being used. In order to early detect ototoxicity, patients being treated with antibiotic agents should be weekly assessed; and in extreme cases, every 2 or 3 days. Those patients being treated with platin analogues (cisplatin and carboplatin) should undergo audiological evaluations within 24 hours of chemotherapy onset.

Thus, ASHA $^{25}$ recommended a protocol that first stresses the medical interview, followed by otoscopy and, later, the hearing assessment made up of a threshold tonal audiometry and a high frequency audiometry, logoaudiometry and acoustic immittance measures. Such association suggests that both logoaudiometry and acoustic immittance measure should be carried out as soon as the first evaluation is performed, but they do not have to be done again in the successive evaluations, unless there are threshold changes. Moreover, they suggest that EOE and BERA should be carried out when the patient is unable to respond to subjective testing.

Some studies show that the BERA is efficacious in the early detection of cisplatin-induced hearing loss, by following Wave $\mathrm{V}$ as a minimum hearing level ${ }^{26-28}$.

High frequency audiometry is being mentioned in the international literature as a sensitive procedure in the early detection of hearing alterations caused by ototoxic medication, and many investigators have stated that hearing monitoring is fundamental in order to avoid degenerative processes occurring to the cochlea spiral process $^{7,11,13,16,17,20,25,28-33}$, although there is still no consensus as to the criteria used for results interpretation. Park ${ }^{20}$ recommends the use high frequency audiometry, followed by pure tone audiometry and the investigation of acoustic reflexes, in this order. In order to record high frequency thresholds, the patient's participation is paramount in order to achieve a reliable result, having in mind that this is a behavioral and subjective evaluation ${ }^{34}$. 
Table 1. Results summary from some studies classified according to drug type and ototoxic effect.

\begin{tabular}{|c|c|c|c|c|c|}
\hline & & & & TOXIC EFFECTS & \\
\hline & AUTHOR / YEAR & DRUG & COCLEO TOXIC & VESTIBULOTOXIC & NEURO TOXIC \\
\hline \multirow{4}{*}{$\begin{array}{l}\text { Aminoglicoside anti- } \\
\text { biotics }\end{array}$} & Schacht (1993) & Streptomycin & + & + & - \\
\hline & $\begin{array}{l}\text { Matz, Rohn Meyerhoff e Wri- } \\
\text { ght (1993) }\end{array}$ & Neomycin & + & - & - \\
\hline & Matz (1993) & Amikacin & + & - & - \\
\hline & Matz (1993) & Kanamycin & + & - & - \\
\hline \multirow{7}{*}{ Other antibiotics } & $\begin{array}{l}\text { Stupp (1973); Oliveira (1986); } \\
\text { Brummett (1993) }\end{array}$ & Erythromycin & + & - & - \\
\hline & Brummett (1993) & Vancomycin & + & + & - \\
\hline & $\begin{array}{l}\text { Patterson e Gulik (1969); } \\
\text { Rohn, Meyerhoff e Wright } \\
(1993)\end{array}$ & Chloramphenicol & + & - & - \\
\hline & Oliveira (1986) & Ampicillin & - & + & - \\
\hline & Oliveira (1986) & Minocycline & - & + & - \\
\hline & Oliveira (1986) & Capreomycin & + & + & - \\
\hline & Oliveira (1986) & Colistin & + & - & - \\
\hline \multirow{2}{*}{ Topical Agents } & Morionza e Sikora (1981) & Antiseptic (alcohol) & + & - & - \\
\hline & Parker e James (1978) & $\begin{array}{l}\text { Antifungal (Ggriseo- } \\
\text { fulvin) }\end{array}$ & + & - & - \\
\hline Loop diuretics & $\begin{array}{l}\text { Boston Collaborative Drug } \\
\text { Sevillance Program (1973) }\end{array}$ & Furosemide & + & + & - \\
\hline \multirow{5}{*}{$\begin{array}{l}\text { Chemotherapeutic } \\
\text { agents }\end{array}$} & $\begin{array}{l}\text { Carenza Vellani e Kinngston } \\
\text { (1986); Otto (1988); Schweit- } \\
\text { zer (1993) }\end{array}$ & Cisplatin & + & + & + \\
\hline & $\begin{array}{l}\text { Schucknecht (1979); Schweit- } \\
\text { zer (1993) }\end{array}$ & $\begin{array}{l}\text { Nitrogenated Mus- } \\
\text { tard }\end{array}$ & + & - & - \\
\hline & Schweitzer (1993); & $\begin{array}{l}\text { 6-amino nicotinamide } \\
\text { (6-NA) }\end{array}$ & + & - & + \\
\hline & Serafy (1981) & Vincristine sulphate & + & - & + \\
\hline & Schweitzer (1993); & Misonidazole & + & - & - \\
\hline
\end{tabular}

Legend: (+) ototoxic effect present; (-) ototoxic effect absent 
Fausti et al. ${ }^{17}$ proposed a testing procedure in five frequencies $(8 \mathrm{kHz}, 9 \mathrm{kHz}, 10 \mathrm{kHz}, 12.5 \mathrm{kHz}$ and $16 \mathrm{kHz})$ as an alternative monitoring protocol for those patients exposed to cisplatin, since they may not be capable of responding or even tolerating such an intense array of audiological tests.

As we analyze the specific literature on the use of EOE in the auditory monitoring for ototoxic-drug-exposed patients, we see that it evaluates the cochlear bioactive mechanism corresponding to the external hair cell responses within the cochlea. According to Kemp ${ }^{35}$ \& Probst et al. ${ }^{36}$, transient stimulus evoked otoacoustic emissions (TEEOE) are almost always present in individuals who have audiometric thresholds higher than 30 dBHL. However, investigators such as Desai et al. ${ }^{37}$ and Prasher \& Sulkowski ${ }^{38}$ stated that, when there is an initial involvement of the external hair cells, the TEEOE may be absent, even under normal hearing thresholds.

Because of this very property, this procedure has been used in hearing monitoring in order to check cochlear alterations caused by ototoxic drugs, by means of reducing the amplitude of emissions before alterations happen to the tonal thresholds $s^{8,9,21,22,39-46}$. Moreover, this is an objective analysis (and not behavioral), that may be carried out even when the child is asleep.

Paz et al. ${ }^{47}$ concluded in their studies that $100 \mathrm{mg} /$ $\mathrm{m}^{2}$ of cisplatin caused a reduction in the transient stimulus evoked otoacoustic emissions and in the distortion product evoked otoacoustic emissions (DPEOAE), more prominently in the high frequencies and directly related to dose build up. They also stated that this reduction in emission amplitudes happens even before tinnitus and subjective hearing loss onset, saying that both TEEOE and DPEOAE are useful methods for the early detection of cisplatin-induced hearing loss and that they complement each other.

Within this context, DPEOAE is more sensitive in the early detection of hearing alterations when compared to TEEOE, since it assess a broader frequency range, including higher frequencies, which are the ones normally affected by ototoxic medication ${ }^{14}$.

Jacob et $a .^{48}$ researched on the EOAE and high frequency audiometry in 44 cancer patients with ages ranging between 3 and 28 years who were being treated by chemotherapy. The results of both tests were then compared to those from the control group (without hearing complaints or exposed to risk factors), and they noticed that high frequency audiometry was more sensitive in the early detection of hearing alterations. Notwithstanding, the same authors highlighted that the choice of procedure to be used in auditory monitoring, in other words, the option of carrying out auditory monitoring by means of high frequency audiometry or evoked otoacoustic emissions depends on two factors: (1) the specific characteristics of the individual being treated, such as: age, capacity to answer behavioral tests, and the patient's clinical status (general health); (2) the goals of the team responsible for the patient that intends to undergo hearing monitoring. After pondering on these two factors, the authors recommend the inclusion of EOAE in the hearing assessment protocol.

\section{DISCUSSION}

There is no doubt that hearing monitoring in individuals exposed to ototoxic medication, by means of highly sensitive and specific procedures, is crucial in order to identify hearing alterations before those more significant frequencies for speech intelligibility are affected. This statement is even more pertaining for the pediatric population undergoing treatment with potentially ototoxic medication, since hearing may seriously compromise their speech acquisition and development and, consequently, bring about difficulties in their psychosocial and learning development.

Physicians increasingly want to know more about drugs that may damage the human hearing apparatus, in an attempt to preserve a patient's hearing function, and thus, such ototoxic drugs are increasingly less present in the therapeutic arsenal.

However, in many situations the use of such drug is unavoidable, as is the case of cancer patients under chemotherapy. In such cases, preserving the patient's life is the ultimate therapeutic goal. Notwithstanding, since the knowledge on different types of chemotherapeutic agents and other ototoxic drugs has been increasing, early diagnosis and, consequently, the cure of cancer are increasingly more present in oncology wards, especially in pediatric oncology. Therefore, cancer treatment success must be associated to a concern with the patient's well being and his/her quality of life, including hearing care.

Thus, auditory assessment is essential for those individuals exposed to high doses of chemotherapeutic agents, for ototoxicity identification and rehabilitation purposes. Hearing tests should be carried out before and after the onset of ototoxic medication deployment, so that the patient may be properly followed up.

We should also stress the importance of always asking both the patient and his/her family about the recent use of ototoxic drugs, family or personal history of hearing impairment, and pay close attention to the use of another concurrent ototoxic drug. Such information is very useful in order to survey risk indicators for hearing loss, since the synergy of different ototoxic agents may enhance their effect on hearing. Moreover, the use of different ototoxic agents is commonly done in chemotherapy. 
Our survey and reading of the national research on this theme lead us to make some analysis. Publications in this field are scarce, and the existing ones are restricted to pointing out the deleterious consequences of ototoxic drugs on hearing, but do not present evidences on the thresholds of ototoxic drug use in order to prevent or mitigate the ototoxicity severity ${ }^{6,7,10,13,18,19,23,33,45,48,49}$.

Such statement elicits some considerations. First it highlights the difference in the multidisciplinary care given to individuals under chemotherapeutic care in Brazil when compared to places like the United States and some European countries.

Our settings are somewhat different from that of these countries, for they count on financial investment for the development of research in this field. Thus, the difficulties in obtaining research grants for studies in the most diverse health fields do restrict the necessary magnitude of these types of scientific investigations. In such a context, we discuss some aspects that are paramount for the hearing monitoring procedures used by large centers abroad and also in the care of individuals exposed to chemotherapeutic agents or other types of ototoxic drugs.

First, we list the easy access these individuals have towards hearing assessments which are carried out within the person's treatment venue (ideally) or even in the ease of transportation towards specialized centers where these assessments are carried out. In Brazil, it is not routine in most of the large centers that treat individuals with potentially ototoxic medication, such as the oncology wards, to offer effective auditory monitoring for those patients that start on cancer treatment. As a major difficulty towards performing such monitoring we stress the lack of an audiology department that makes the equipment for such evaluation available. Moreover, there still is an important underreferral of these patients to the otorhinolaryngologist for proper audiologic assessment.

Another very relevant aspect is a precise medication control and their proper dosing, among other factors, by the results attained in audiological tests, seeking efficient alternatives for the treatment of cancer or other diseases aiming at hearing preservation. In this direction, hearing monitoring is fundamental, and bearing in mind the individual's susceptibility for hearing loss, the physician should not be stuck only to medication dosage in order to predict whether or not there is a risk for ototoxicity ${ }^{25}$.

Specialized literature provides hearing assessent protocols for this population, however, we still lack a consensus among researchers on which should be the most adequate protocol to be used in hearing monitoring.

Thus, it is necessary to make a few comments regarding each procedure used in the hearing monitoring of individuals who are being treated by ototoxic medication.

Threshold tonal audiometry comes up as one of the procedures used for this end $\mathrm{d}^{6,7,13,18,20,23,25}$, however, it is important to clarify that it should be carried out aiming at investigating the patient's hearing acuity before treatment onset, since this procedure is not very sensitive for the early detection of hearing alterations.

High frequency audiometry has been considered the method of choice by some investigations, because it allows for hearing alterations detection before the most significant frequencies for communication are affected $^{7,11,13,16-}$ 18,20,28-33,49.

When we think that the drug-induced hearing alterations happen in the basal turn of the cochlea, first affecting the high frequencies ${ }^{16-22}$, and the many papers that mention this procedure as efficient for the early detection of ototoxicity, high frequency audiometry should be part of the hearing monitoring protocol. Notwithstanding, it is important to clear up that since it is a behavioral method used to assess hearing, and depending on the child's age, neurological status or the patient's general health status, such procedure may not be possible.

Under such assumptions, it is recommended to include otoacoustic emissions in the assessment protocol when the patient is unable to respond to the behavioral tests, having seen that many papers confirm its clinical application on the early detection of ototoxicity $8,9,14,21,22,39-$ ${ }^{48,50}$. It is worth stressing that, as aforementioned, since the frequency range assessed in TEEOE is carried out between 1 and $4 \mathrm{kHz}$, DPEOAE should not be excluded, because TEEOE may be present even when there are alterations in the outer hair cells in the most basal portion of the spiral organ (base membrane vibration for those sounds in frequencies above $4 \mathrm{kHz})^{48}$. In these cases, considering that the DPEOAE investigate the cochlear amplification mechanism at a higher frequency range, such alterations may be detected from the reduction in response amplitude or its absence in the higher frequencies.

As one includes EOAE in the evaluation protocol, it is paramount to perform immittance measures during the same assessment session, so that the investigator may safely interpret if a drop in EOAE amplitude or its absence happened because of a defect on the amplifying mechanism of the outer hair cells or because of some middle ear transmission mechanism alteration. Immittance measures may be also used to detect the presence of the stapedial reflex, offering the possibility of confirming the presence of a Metz recruitment, since ototoxicity causes cochlear lesion.

When one performs hearing monitoring by means of high frequencies audiometry, or using otoacoustic emissions, one must necessarily have an assessment made prior to medication onset, since responses may vary within normality. Moreover, the results of both evaluations are influenced by age, by prior hearing impairment in the 
high frequencies, and there may also be EOAE amplitude reduction, non-medication related.

At last, considering the pediatric population, another method to assess hearing, but limited for the early detection of ototoxicity, is the Brain Stem Evoked Response Audiometry (BERA). Although much used in the clinical routine for obtaining the electrophysiological threshold, it does not assess responses in the high frequencies (above $4 \mathrm{kHz}$ ) where the cochlea is affected by ototoxic drug exposure. Notwithstanding, such procedure may and should be used to monitor those individuals exposed to neurotoxic agents.

The hearing monitoring protocol must be structured according to the particular characteristics of each individual patient, such as age, capability to respond to the tests, clinical status, and others. Thus, as procedures for hearing evaluation and monitoring we suggest:

1. For individuals who do not respond to behavioral hearing evaluation:

1.1 - on the first assessment and on the subsequent ones:

- Transient stimulus and distortion product evoked otoacoustic emissions recording;

- Acoustic immittance measures (tympanometry and contra and ipsilateral acoustic reflex thresholds);

- Brain Stem Evoked Response Audiometry, including electrophysiological threshold testing.

In some cases, the child may present inconsistent responses in the pure tone threshold recording, but provide consistent answers on the speech recognition threshold or speech detectability by means of figures or simple verbal commands. This information is deemed extremely useful in order to assess a child's hearing when he/she has been submitted only to EOAE. If there is reduction in these thresholds in subsequent evaluations, coupled with amplitude reduction in EOAE responses, hearing sensitivity deterioration becomes more evident and should be considered.

2. For both children and adults responders to behavioral hearing assessment:

2.1 - On the first assessment:

- Threshold tonal audiometry and logoaudiometry;

- Acoustic immittance measures (tympanometry and acoustic reflex threshold acquisition contra and ipsilateral);

- High frequency audiometry in 4 frequency ranges;

- DPEOAE and TEEOE;

- Brain Stem Evoked Response Audiometry when the medication used is potentially neurotoxic.

2.2 - On subsequent assessments:

- High frequency audiometry in four frequency ranges;

- Brain Stem Evoked Response Audiometry when the medication used is potentially neurotoxic.

Threshold tonal audiometry and the EOAE recordings may be carried out on subsequent assessments if there is any worsening in the high frequencies audiometry results (worsening in the threshold equal to or greater than $15 \mathrm{~dB}$ in at least two frequencies evaluated between 500 and $4000 \mathrm{~Hz}$ ), the acoustic reflex testing should be carried out in order to investigate recruitment. At this moment, audiometry is paramount, since by means of its results, the team of caregivers will decide on the fitting of a hearing aid.

\section{FINAL REMARKS}

Technological progress has made available numerous resources that can be used for hearing monitoring purposes. Thus, early detection of hearing loss by means of hearing assessment procedures with high sensitivity in the identification of hearing drug-induced hearing alterations is crucial. Moreover, when hearing impairment installs, a hearing monitoring program may provide the individual with the early option for selection, indication and fitting of an individual hearing amplification device (IHAD), as well as hearing rehabilitation.

\section{REFERENCES}

1. Oliveira JAA, Canedo DM, Rossato M. Otoproteçäo das células ciliadas auditivas contra a ototoxicidade da amicacina. Rev Bras Otorrinolaringol 2002;68(1):7-13.

2. Alvarenga KF, Jacob LCB, Martins CHF, Costa AO, Coube CZV, Marques JM. Emissöes otoacústicas - produto de distorçäo em indivíduos expostos ao chumbo e ao ruído. Rev Bras Otorrinolaringol 2003;69(5):681-6.

3. Morata TC. Chemical exposure as a risk factor for hearing loss. J Occup Environ Med 2003;45(7):676-82.

4. Teixeira CF, Augusto LG, Morata TC. Saúde auditiva de trabalhadores expostos a ruído e inseticidas. Rev Saúde Publica 2003;37(4):417-23.

5. Berg AL, Spitzer JB, Garvin JH Jr. Ototoxic impact of cisplatin in pediatric oncology patients. Laryngoscope 1999;109(11):180614.

6. Dishtchekenian A, Iorio MCM, Petrilli AS, Azevedo MF. Monitorização auditiva na ototoxicidade In: Barros A et al. Fonoaudiologia em Cancerologia, São Paulo, Fundação Oncocentro, 2000b, 260269.

7. Dishtchekenian A, Iorio MCM, Petrilli AS, Paiva ER, Azevedo MF. Acompanhamento audiológico em pacientes com osteossarcoma submetidos à quimioterapia com cisplatina. Rev Bras Otorrinolaringol 2000;66 (6):580-90.

8. Ozturan O, Jerger J, Lew H, Lynch GR. Monitoring of cisplatin 
ototoxicity by distortion-product otoacoustic emissions. Auris Nasus Larynx 1996;23:147-51.

9 Stavroulaki P, Apostolopoulos N, Segas J, Tsakanikos M, Adamopoulos G. Evoked otoacoustic emissions--an approach for monitoring cisplatin induced ototoxicity in children. Int J Pediatr Otorhinolaryngol 2001;31,59(1):47-57.

10. Testa JRG. Aspectos otológicos do paciente com câncer de cabeça e pescoço. In: De Angelis EC, Ferreira CLB, Kowalski LP. A atuação da fonoaudiologia no câncer de cabeça e pescoço, São Paulo: Lovise; 2000. p.135-8.

11. Fausti SA, Schechter MA, Rappaport BZ, Frey RH, Mass RE. Early detection of cisplatin ototoxicity. Selected case reports. Cancer 1984;15,53(2):224-31.

12. Aguiar F. A influência de medicamentos nas funções auditiva e vestibular. Curitiba, 2000, (monografia de conclusão de curso - Universidade Tuiuti do Paraná).

13. Moussalle MM, Rangel M, Baú ALW, Stangler S, Gomes NHG, Moussalle S. Prevenção e abordagem do uso de drogas ototóxicas. Acta Méd 1997;(1):100-8.

14. Mckeage MJ. Comparative adverse effect profiles of platinum drugs. Drug Saf 1995;13(4):228-44.

15. Pasic TR, Dobie RA. Cis-platinum ototoxicity in children. Laryngoscope 1991;101(9):985-91.

16. Fausti SA, Frey RH, Henry JA, Olson J, Schaffer HI. High-frequency testing techniques and instrumentation for early detection of ototoxicity. Journal Rehabilitation Res Development 1993;30(3):33341.

17. Fausti SA, Henry JA, Helt WJ, Phillips DS, Frey RH, Noffsinger $\mathrm{D}$ et al. An Individualized, sensitive frequency range for early detection of ototoxicity. Ear Hear 1999;20(6):497-505.

18. Garcia AP, Iório MCM, Petrilli AS. Monitoramento da audição de pacientes expostos à cisplatina. Rev Bras Otorrinolaringol 2003;69(2):215-21.

19. Oliveira JAA. Ototoxidade. In: Costa SS, Cruz OLM, Oliveira JAA et al. Otorrinolaringologia: Princípios e Prática. Porto Alegre: Artes Médicas; 1994.

20. Park KR. The utility of acoustic reflex thresholds and other conventional audiologic tests for monitoring cisplatin ototoxicity in the pediatric population. Ear Hear 1996;17(2):107-15.

21. Littman TA, Magruder A, Strother DR. Monitoring and predicting ototoxic damage using distortion-product otoacustic emissions: pediatric case study. J Am Acad Audiol 1998;9(4):257-62.

22. Yardley MP, Davies CM, Stevens JC. Use of Transient evoked otoacoustic emissions to detect and monitor cochlear damage caused by platinum- containing drugs. Br J Audiol 1998;32(5):30516.

23. Borges GC, Borges RHM, Baraúna GN, Filho OL. Ototoxicidade Causada pela Cisplatina em Crianças. Estudo Retrospectivo. Rev Bras Otorrinolaringol 2001;67(3):292-5.

24. Penido NO, Mota PHM, Mascari DSA, Fukuda Y. Ototoxicidade induzida por cis-diamminedichloroplatinum (NSC - 119875). Acta Awho 1989;(8):80-3.

25. American Speech-Language-Hearing Association audiologic management of individuals receiving cochleotoxic drug therapy. Guidelines for the audiologic management of individuals receiving cochleotoxic drug therapy. ASHA, 1994;36(suppl. 12):119

26. Cevette MJ, Drew D, Webb TM, Marion MS. Cisplatin ototoxicity, increased DPOAE amplitudes, and magnesium deficiency. Distortion product otoacoustic emissions. J Am Acad Audiol 2000;11(6):323-9.

27. De Lauretis A, De Capua B, Barbieri MT, Bellussi L, Passàli D. ABR evaluation of ototoxicity in cancer patients receiving cisplatin or carboplatin. Scand Audiol 1999;28(3):139-43.

28. Fausti SA, Frey RH, Henry JA, Olson J, Schaffer HI. Early detection of ototoxicity using high-frequency, tone burst-evoked auditory brainsteam responses. J Am Acad Audiol 1992;3(6):397-404.

29. Dreschler WA, Van Der Hulst RJ, Tange RA, Urbanus NA. Role of high-Frequency Audiometry in early detection of ototoxicity. Audiology 1989;28(4):211-20.

30. Fausti SA, Larson VD, Noffsinger D, Wilson RH, Phillips DS, Fowler CG. High-frequency audiometric monitoring strategies for early detection of ototoxicity. Ear Hear 1994;15(3):232-9.

31. Feghali JG, Bernstein RS. A new approach to serial monitoring of ultra-high frequency hearing. Laryngoscope 1991;101(8):825-9.

32. Tange RA, Dreschler WA, Van Der Hulst RJ. The importance of high-tone audiometry in monitoring for ototoxicity. Arch Otorhinolaryngol 1985;242(1):77-81.

33. Zeigelboim BS, Mangabeira-Albernaz PL, Fukuda Y. Audiometria de Altas Freqüências: Monitoramento Auditivo. Temas em ORL \& Cirurgia de Cabeça e Pescoço 2001;2:21-25.

34. Simpson TH, Schwan SA, Rintelmann WF. Audiometric test criteria in the detection of cisplatin ototoxicity. J Am Acad Audiol 1992;3(3):176-85.

35. Kemp DT. Evidence of mechanical nonlinearity and frequency selective wave amplification in the coclear. Arch Otorhinolaryngol 1979;224(1-2):37-45.

36. Prosbt R, Coats A, Martin G, Lonsbury-Martin B. Spontaneous, click a tone burst-evoked emissions from normal ears. Hear Res 1986;21(3):261-75.

37. Desai A, Reed D, Cheyne A, Reichards S, Prasher D. Absence of otoacoustic emissions in subjects with normal audiometric thresholds implies exposure to noise. Noise Health 1999;1(2):5865 .

38. Prasher D, Sulkowski W. The role of otoacoustic emissions in screening and evaluation of noise damage. Internat J Occup Med Environ Health 1999;12(2):183-92.

39. Beck A, Maurer J, Welkoborsky HJ, Mann W. Changes in transitory evoked otoacoustic emissions in chemotherapy with cisplatin and 5FU. HNO 1992;40(4):123-7.

40. Hotz MA, Harris FP, Probst R. Otoacoustic emissions: an approach for monitoring aminoglycoside-induced ototoxicity. Laryngoscope 1994;104(9):1130-4.

41. Orts Alborch M, Morant Ventura A, Garcia Callejo J, Ferrer Baixauli F, Martinez Beneito MP, Marco Algarra J. Monitoring drug ototoxicity with distortion products. Acta Otorrinolaringol Esp 2000;1(5):387-95.

42. Plinkert PK, Kröber S. Early detection of cisplatin-induced ototoxicity using evoked otoacoustic emissions. Laryngorhinootologie 1991;70(9):457-62.

43. Stavroulaki P, Apostolopoulos N, Dinopoulou D, Vossinakis I, Tsakanikos M, Douniadakis D. Otoacoustic emissions - an approach for monitoring aminoglycoside induced ototoxicity in children. Int J Pediatr Otorhinolaryngol 1999;50(3):177-84.

44. Stavroulaki P, Vossinakis IC, Dinopoulou D, Doudounakis S, Adamopoulos G, Apostolopoulos N. Otoacoustic emissions for monitoring aminoglycoside-induced ototoxicity in children with cystic fibrosis. Arch Otolaryngol Head Neck Surg 2002;128(2):1505.

45. Vallejo JC, Silva MN, Oliveira JAA, Carneiro JJ, Rocha LSO, Figueiredo JFC et al. Detecção precoce de ototoxicidade usando emissões otoacústicas produtivas de distorção. Rev Bras Otorrinolaringol 2001;67(6):845-51.

46. Zorowka PG, Schmitt HJ, Gutjahr P. Evoked otoacoustic emissions and pure tone threshold audiometry in patients receiving cisplatinum therapy. Int J Pediatr Otorhinolaryngol 1993;25(1-3):73-80.

47. Paz I, Codjambassis D, Pinto U. Emissiones Otoacústicas en la Detección Precoz de Ototoxicidad Inducida por Cisplatino. Rev Otorrinolaringol CIR Cabeza Cuello 2000;(60):7-13.

48. Jacob LCB, Stumpf CC, Bitencourt RF, Marques JM, Puppi C, Gon- 
çalves PT. Avaliação audiológica em indivíduos com neoplasias expostos a agentes quimioterápicos. Fono Atual 2005;3:12-25.

49. Santos CF, Valete CM, Martins AG, Ferreira NGM, Tomita S. Aspectos clínicos da ototoxicidade dos aminoglicosídeos. Acta Awho 2000;19(3):160-4.
50. Mulheran M, Degg C. Comparison of distortion product OAE generation between a patient growth requirent frequent gentamicin therapy and control subjects. Br J Audiol 1997;31(1):5-9. 